\title{
Alcohol Consumption and the Incidence of Acute Alcohol- Related Problems
}

\author{
Alexander C. Wagenaar, Ph.D. \\ The University of Michigan, Transportation Research Institute, Ann Arbor, \\ Michigan 48109, U.S.A.
}

\begin{abstract}
Summary
Researchers in recent years have suggested that control of the aggregate level of alcohol consumption is an important component of a comprehensive programme for the prevention of alcohol-related problems. The present study focused on the relationship between alcohol consumption and perhaps the most significant acute alcohol-related problem, motor vehicle crashes. Data analyzed included monthly frequencies of alcohol-related property damage and injury producing motor vehicle crashes and monthly distribution of beer, wine, and distilled spirits in the State of Michigan. To increase confidence that observed correlations represented causal relationships between aggregate consumption and crash involvement, variance in each time series explainable on the basis of its own past history was filtered out first using ARIMA models, with the remaining variance used in analyses of the consumption/crash relationship. Using cross-lagged correlation methods, significant relationships were found between wholesale beer and wine distribution in a given month, and the number of alcohol-related motor vehicle crashes one month later.
\end{abstract}

In the past decade researchers have addressed the issue of whether the overall level of alcohol consumption in a community is related to the level of alcohol-related problems experienced by that community. If it is, one approach to the prevention of alcohol-related problems may be to reduce the aggregate quantity of alcohol consumed [1]. Most studies have focused on the relationship of aggregate consumption to chronic health problems associated with alcohol consumption such as liver cirrhosis. Numerous studies have revealed a positive relationship between aggregate alcohol consumption and cirrhosis rates $[2,3,4]$. This study examined the relationship between the overall level of alcohol use and the incidence of a major acute alcohol-related problem, motor vehicle crashes involving drinking drivers.

This study was designed to overcome three important limitations of the extant research. First, the study reported here uses a longitudinal or time-series approach. Many past studies have been cross-sectional designs, relating alcohol consumption levels in various jurisdictions to their level of alcohol problems. While multivariate methods are coming into increased use, there always remain additional confounding variables distinguishing jurisdictions that may account for observed relationships between alcohol consumption and problems. One way to reduce the confounding-variable problem is to hold a multitude of such factors constant by analyzing a single jurisdiction over time.

Most time-series studies of the relationship between alcohol consumption and alcohol-related problems were based on simple correlations and did not adequately control for the effects of long-term trends and cycles before measuring the relationship between alcohol consumption and damage. Therefore, the second way in which this study was designed to overcome limitations of past research was through controlling for the effects of long-term patterns, particularly seasonal cycles, when measuring the effects of changes in alcohol consumption. Such controls were accomplished by using Box-Jenkins time-series-analysis methods.

Finally, most studies to date have focused on long-term chronic drinking, measured by liver cirrhosis rates, as the alcohol-related health problem most likely to be influenced by aggregate consumption patterns. The study reported here, in contrast, focused on acute alcoholrelated problems. In most western countries, motor vehicle crashes are a leading cause of morbidity and mortality for the first half of the life-span. Approximately half of all traffic fatalities and a quarter of all serious crashinduced injuries involve drinking drivers. Therefore, the 
Table 1. Cross-correlations between alcoholic beverage sales and alcohol-related motor vehicle accidents, raw data

\begin{tabular}{|c|c|c|c|c|c|c|c|}
\hline \multirow{2}{*}{ Variables } & \multicolumn{7}{|c|}{ Number of months lag } \\
\hline & 0 & 1 & 2 & 3 & 4 & 5 & 6 \\
\hline Beer and property-damage accidents & -.27 & -.18 & .00 & .20 & .53 & .58 & .49 \\
\hline Beer and injury accidents & .28 & .36 & .39 & .38 & .40 & .21 & -.02 \\
\hline Wine and property-damage accidents & .27 & .36 & .44 & .22 & .08 & .14 & .21 \\
\hline Wine and injury accidents & .52 & .52 & .42 & .10 & .07 & .13 & .30 \\
\hline Spirits and property-damage accidents & .72 & .15 & -.02 & .22 & -.19 & -.09 & .17 \\
\hline Spirits and injury accidents & .56 & -.03 & -.16 & -.03 & -.18 & .07 & .22 \\
\hline
\end{tabular}

Note: Standard error for all coefficients is .10.

frequency of drinking drivers involved in motor vehicle crashes was used as a measure of acute alcohol-related problems that may be affected by changes in aggregate consumption.

\section{Methods}

The main question addressed in this study is: does a change in the total quantity of alcoholic beverages distributed in a given jurisdiction affect the incidence of alcohol-related motor vehicle crashes? Independent variables were the total quantities of beer, wine, and distilled spirits sold in the State of Michigan each month from January 1972 through December 1980. These data, obtained from the Michigan Liquor Control Commission and Michigan Beer and Wine Wholesalers Association, reflect distribution at the wholesale rather than retail level.

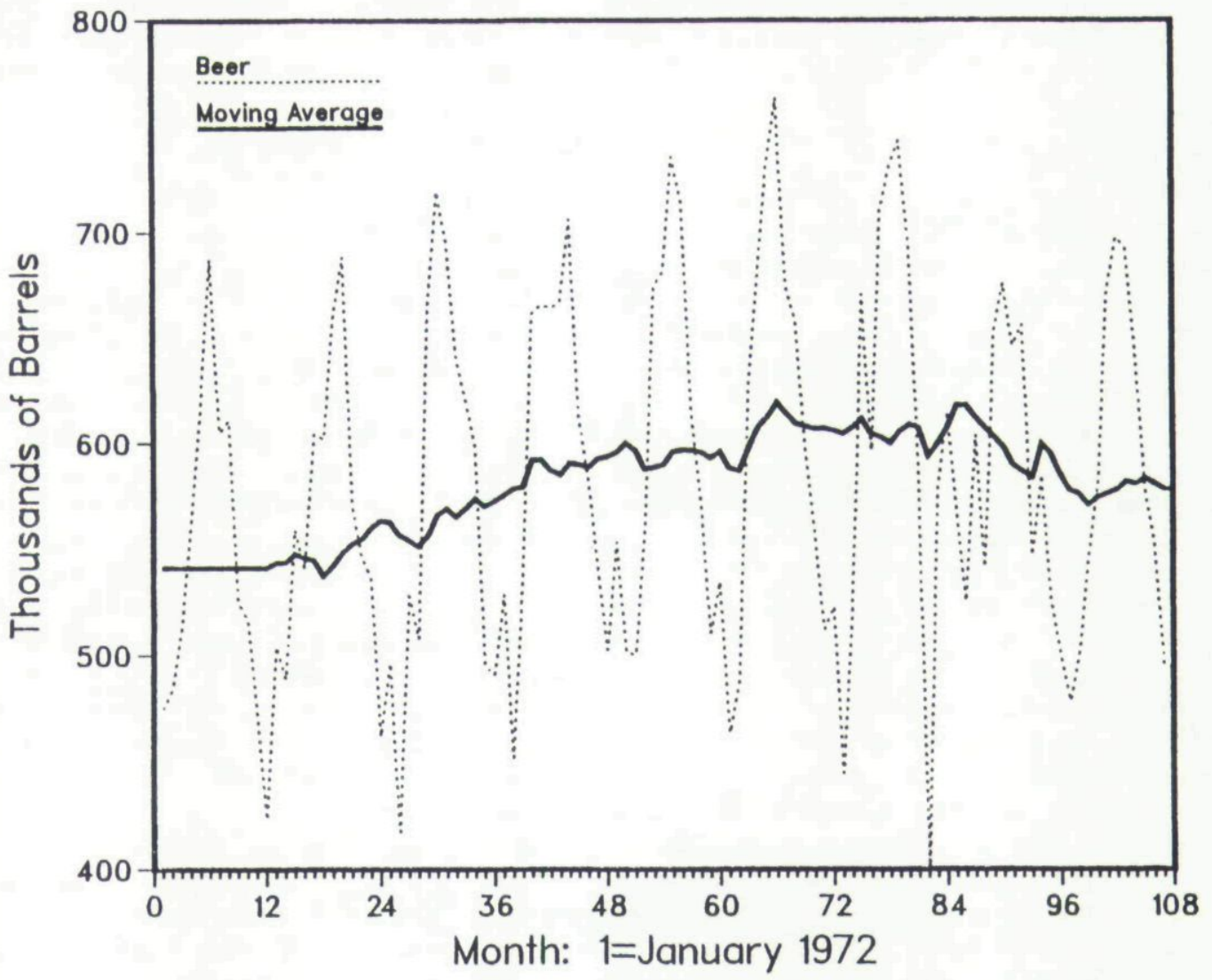

Figure 1. Michigan apparent beer consumption. 
The two dependent variables were the number of drinking drivers involved in (1) property-damage or (2) injury-producing motor vehicle crashes each month for the same jurisdiction and time period. Records on all motor vehicle crashes reported to any police jurisdiction in Michigan from 1972 through 1980 were obtained from the Michigan Department of State Police. Determination of whether or not the driver was drinking at the time of the crash was based on information provided by police officers who investigated the crashes. Michigan includes a separate forced-choice item on a statewide standardized crash report that requires the investigating officer to identify the driver as nondrinking or drinking. This item is not dependent on (1) any complex judgement the alcohol caused the crash, (2) whether the driver was arrested for driving under the influence of alcohol, and (3) results of any blood-alcohol-concentration test that may have been administered. Because this item is not based on these other factors that rely even more on police judgement, the resulting data are a reasonably good indicator of the presence of alcohol in crashes. Past research on this measure of alcohol involvement in Michigan crashes revealed a high degree of convergent validity when compared with indirect measures such as single-vehicle crashes occurring at night [5].

Analyses consisted of cross-lagged correlation methods combined with the Auto-Regressive Integrated Moving Average (ARIMA) modeling strategy developed by Box and Jenkins [6,7]. Cross correlations are measures of association between two time-series variables with one of the variables lagged a particular number of data points. For example, a simple correlation between the monthly sales of alcohol and the monthly number of crashed drivers would measure the degree of simultaneous association between alcohol sales and crashes. A cross correlation at lag 1 would measure the degree of association between sales of alcohol in any given month and the number of crashed drivers 1 month later. Crosscorrelation methods take advantage of the time-ordered nature of the variables to insure that changes in the independent variable occur before associated changes in the dependent variable. The combination of the Box-

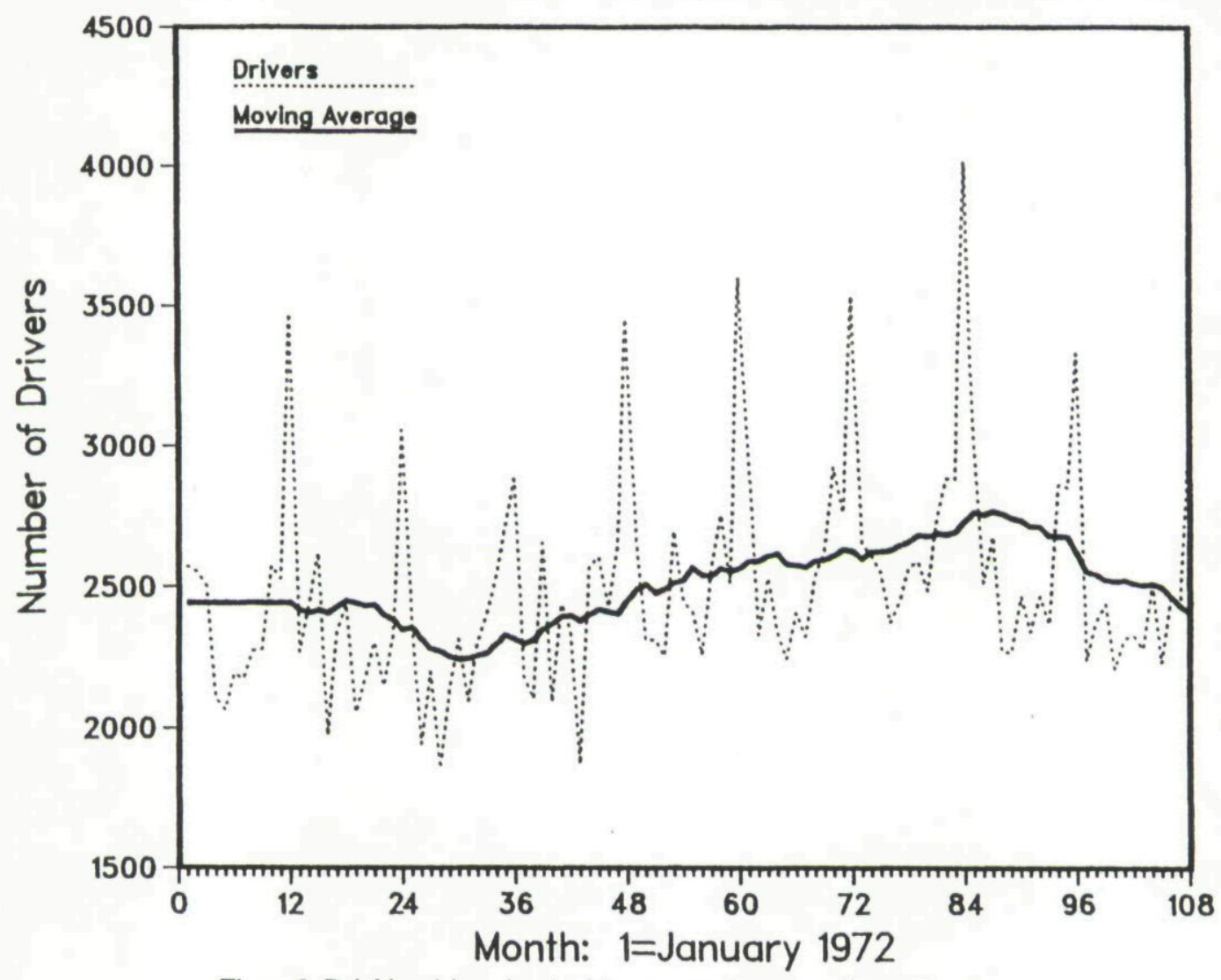

Figure 2. Drinking drivers involved in property damage traffic accidents. 
Jenkins ARIMA models with cross-correlation methods further strengthens the analyses; the ARIMA models control for the potentially confounding influence of longstanding trends and cycles that are a reflection of causally extraneous variables.

\section{Results}

Bivariate correlations between each alcohol consumption indicator and alcohol-related traffic crashes were examined. Because alcoholic beverage sales were measured at the wholesale level, a lag of 2 weeks to 2 months was expected between observed alcohol distribution and its hypothesized effect on traffic crashes. To take this lag structure into account, the simultaneous correlation (i.e., lag 0 ) and cross-correlations (at lags 1 through 6 months) were calculated for each relationship examined. Results, shown in Table 1, indicated large positive correlations between the quantities of beer, wine, spirits distributed at the wholesale level in a given month and the numbers of drinking drivers involved in injury and property-damage traffic crashes over the subsequent several months. With only one exception (beer and property damage crashes at lag 0 ), all significant correlation coefficients are positive. These results are consistent with the hypothesis that the amount of alcoholic beverages sold is associated with the number of crash-involved drinking drivers.

The first row of Table 1 shows the large positive correlations between beer sales and property-damage crashes at lags of 4 to 6 months. These relationships are at too long of a lag to represent the effect of aggregate beer consumption on driving. An important confounding factor is the presence of seasonal cycles that characterize both beer sales and property-damage crashes. Beer sales tend to be highest in the late summer months (Fig. 1), while alcohol-related property damage crashes are most numerous in December (Fig. 2). These two out-of-phase cycles probably account for the high correlations at lags of 4 to 6 months.

Correlations between beer sales and injury crashes are high at lags 0 through 4 . While these correlations may reflect an effect of alcohol sales on crash involvement, they are also contaminated by the normal seasonal cycles in

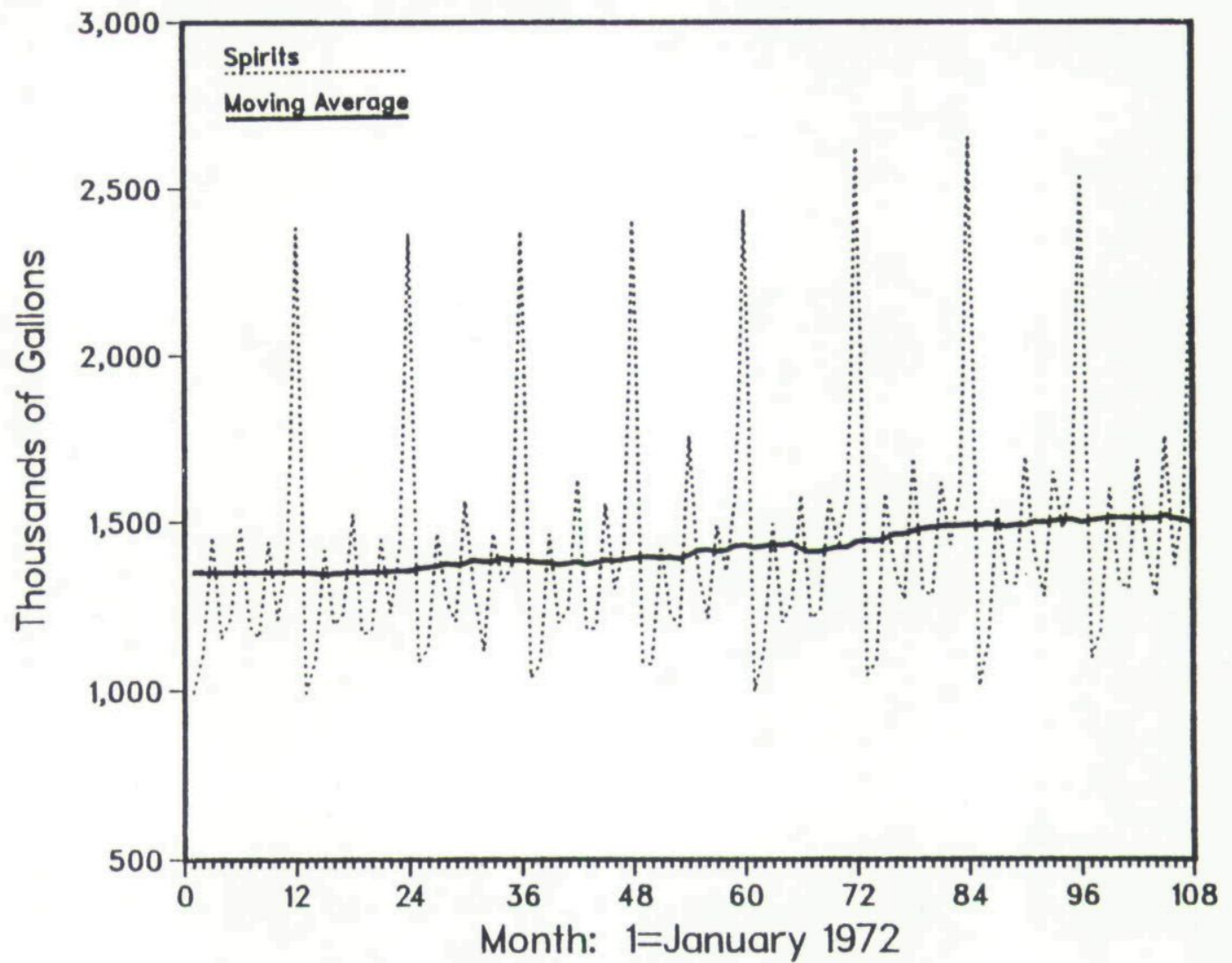

Figure 3. Drinking drivers involved in injury traffic accidents. 
both beer sales and crashes. Alcohol-related injuryproducing crashes, like alcohol-related property damage crashes, are most numerous in December. The last 6 months of each year are generally characterized by increasing numbers of crash-involved drinking drivers, with December consistently the peak month (Fig. 3). The relatively high-crash-frequency months of late summer and fall overlap the months of highest beer sales, causing the moderately high correlations between the beer and accident time series.

Because cycles in both beer sales and alcohol-related crashes are partially a result of exogenous seasonal effects, the high correlation between beer sales and alcoholrelated crashes cannot simply be interpreted as a causal effect of beer sales on crashes. Exogenous seasonal effects refer to the many differences in both drinking patterns and driving patterns due to the time of year under consideration. Vacation travel, recreational driving, weather conditions, holidays, and other seasonal factors influence both drinking and driving-after-drinking. As a result of these confounding factors, a confluence of cycles in these two variables cannot be unambiguously attributed to a causal effect between the two series.

A high degree of association was also found between wine sales (Fig. 4) and both property-damage and injuryproducing crashes (at lags 0 through 2; see Table 1). As with beer sales, these correlations may represent a causal effect of wine sales on the frequency of drinking drivers involved in crashes. However, the confounding seasonal effects makes such a conclusion premature.

The relationship between spirits sales and the number of crash-involved drinking drivers is significantly different than beer or wine. The large correlations are limited to concurrent (lag 0 ) relationships between spirits sales and both property-damage and injury-producing crashes involving drinking drivers. An examination of spirits sales (Fig. 5) indicates that most of the variation in sales is due to a very large amount of spirits sold in December of each year (compared to the average monthly sales the rest of the year). Since the number of drinking drivers involved in crashes also frequently peaks in December, a high concurrent correlation between spirits sales and crashes is

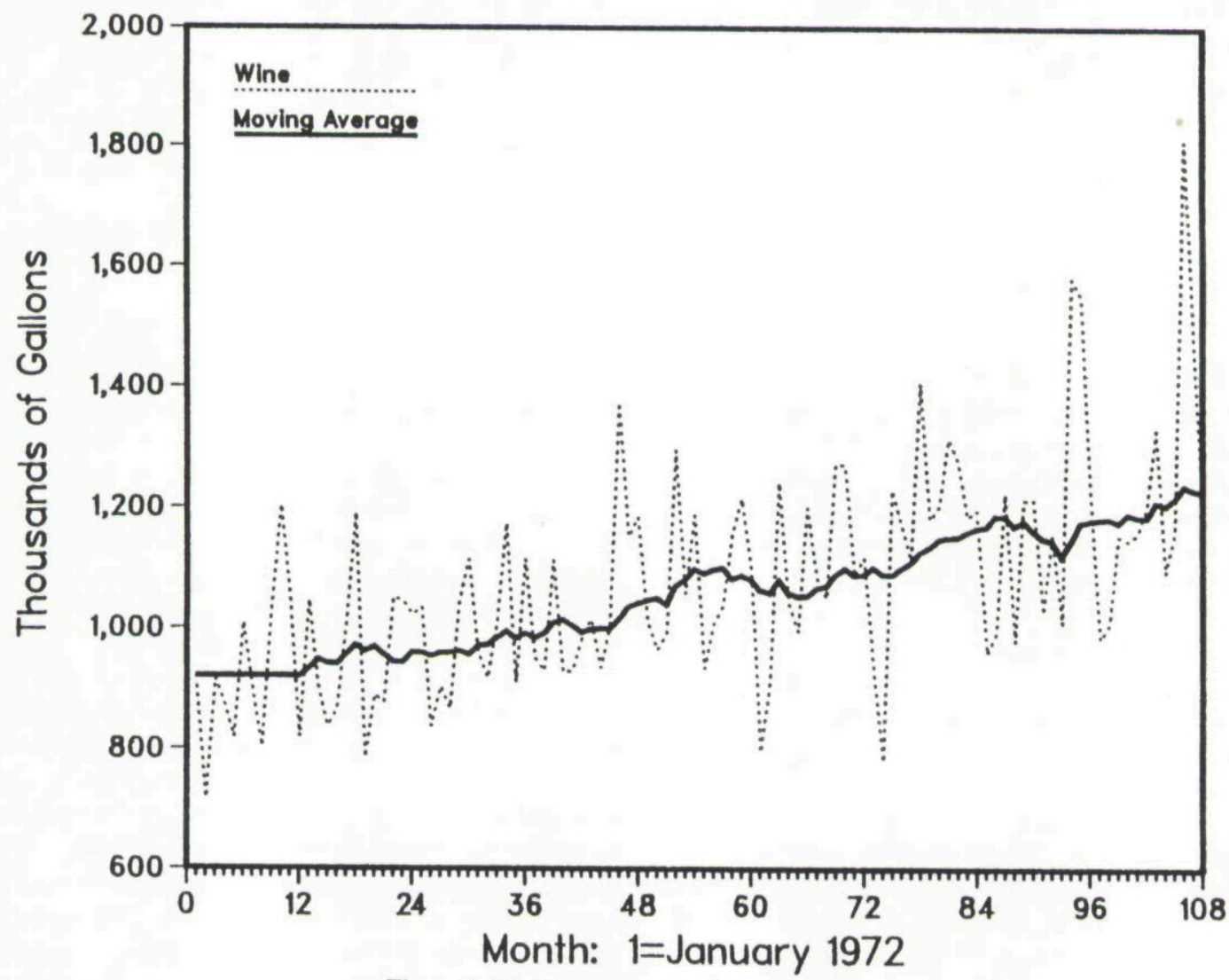

Figure 4. Michigan apparent wine consumption. 


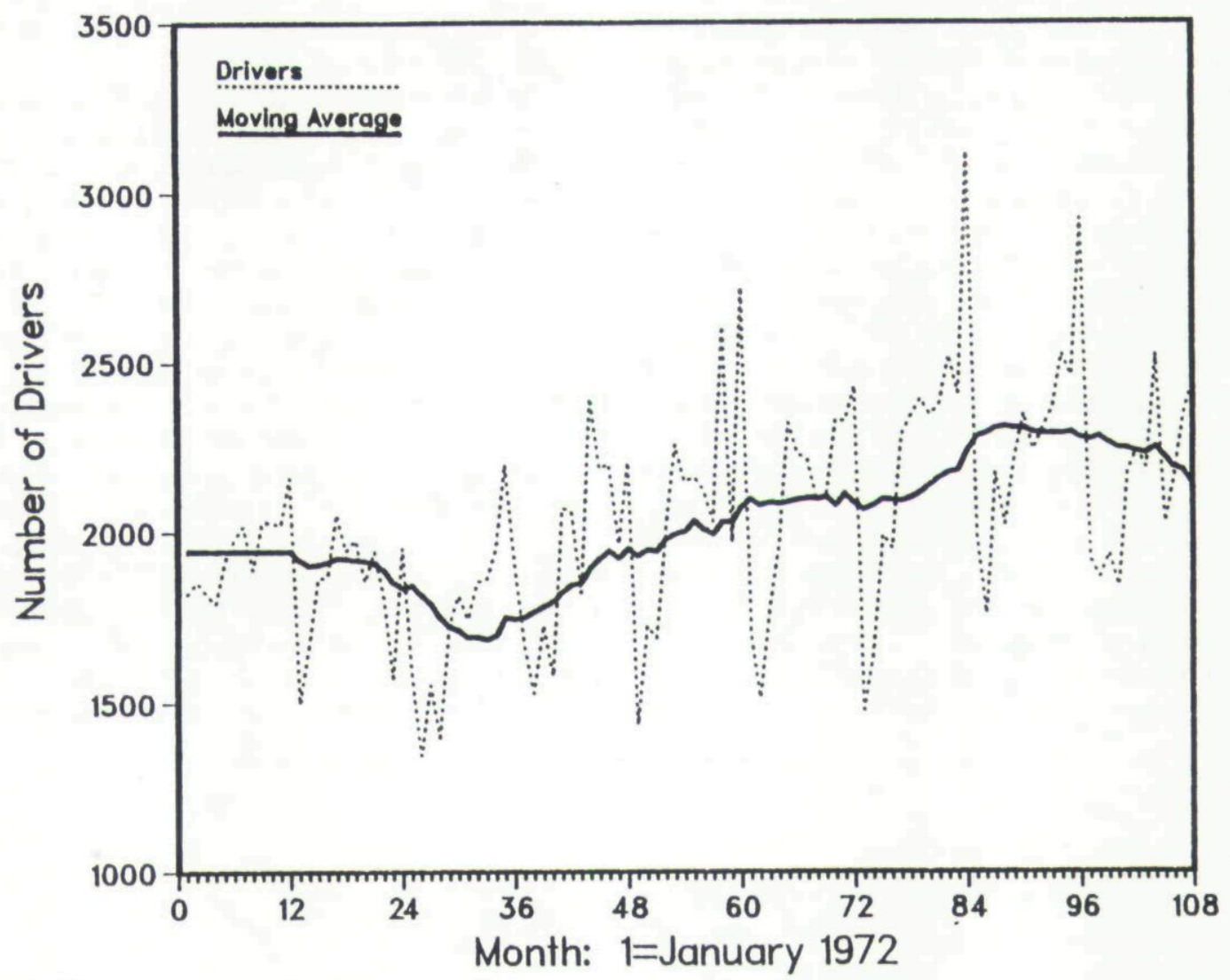

Figure 5. Michigan apparent spirits consumption.

observed. It is certainly plausible to attribute the high levels of alcohol-related crashes in December to high spirits consumption levels. However, there may also be other factors occurring in December, other than high spirits sales, that may contribute to the high crash rates.

In short, interpretation of the correlations shown in Table 1 is complicated by the influence of confounding seasonal effects. Numerous exogenous effects that occur differentially across months of the year are reflected in seasonal cycles in alcohol consumption and alcoholrelated traffic crashes. To more adequately assess underlying relationships between alcoholic beverage sales and alcohol-related traffic crashes, the seasonal effects in each variable were controlled through the use of AutoRegressive Integrated Moving Average (ARIMA) timeseries models. The iterative model building procedures suggested by Box and Jenkins were followed. Specific modeling results are shown in the Appendix for those familiar with these methods. The models accounted for all of the observed regularities (primarily seasonal cycles) in each variable and explained 59 to 98 per cent of the variance in the original series. Residuals from each model represented random month-to-month variation in beverage sales or traffic crashes that cannot be predicted on the basis of past history. The independently distributed residuals from each model were crosscorrelated in the same way as the original data. Resulting cross-correlations are shown in Table 2.

It is important to realize the implications of filtering each variable by an ARIMA model before computing the cross-correlations, even if the reader is not familiar with ARIMA modeling methods. ARIMA models of alcohol sales and crash involvement typically account for about three-fourths of the variance in these indicators by Because measurement and other random error is a much larger proportion of the residual variance than the original series, analyses of the ARIMA residuals provided a conservative test of possible causal effects. Moreover, any 
Table 2. Cross-correlations between alcoholic beverage sales and alcohol-related motor vehicle crashes, controlling for seasonal effects

\begin{tabular}{|c|c|c|c|c|c|c|c|}
\hline \multirow{2}{*}{ Variables } & \multicolumn{7}{|c|}{ Number of months lag } \\
\hline & 0 & 1 & 2 & 3 & 4 & 5 & 6 \\
\hline Beer and property-damage accidents & .15 & .13 & -.08 & -.23 & .22 & .15 & .02 \\
\hline Beer and injury accidents & .20 & .24 & -.02 & -.10 & .11 & .07 & .02 \\
\hline Wine and property-damage accidents & .03 & .30 & -.19 & .02 & .08 & .08 & .03 \\
\hline Wine and injury accidents & .04 & .33 & -.04 & -.04 & .02 & -.12 & .09 \\
\hline Spirits and property-damage accidents & .06 & .10 & -.09 & -.04 & .00 & -.11 & -.08 \\
\hline Spirits and injury accidents & .02 & -.01 & -.08 & -.08 & .11 & -.06 & .03 \\
\hline
\end{tabular}

Note: Standard error for all coefficients is . 10 .

causal effects between alcohol sales and crash involvement that are reflected in the similar cycles in both variables are ignored when analyzing the residual cross-correlations. If

ti the number of drinking drivers involved in crashes follows

4. a regular cycle because alcohol sales follow such a cycle, this effect is not measured in the residual cross-correlations. Only the relationship between random month-to-month changes in sales and similar changes in alcohol-related crashes are measured. As a result, these analyses must be considered a conservative test of the relationship between aggregate alcohol sales and traffic crashes.

As expected, the residual cross-correlations in Table 2 are smaller than the raw cross-correlations in Table 1. Statistically significant correlations remain, however, even after controlling for seasonal effects through the use of ARIMA models. Beer sales and the frequency of alcohol-related property-damage crashes are negatively correlated at lag 3 and positively correlated at lag 4 (see first row of Table 2). Reasons for this lag structure are not clear. The effect of wholesale distribution of beer on traffic crashes was expected within 2 to 10 weeks, as the beverage is consumed, not 4 months later. While an adequate explanation of the lag 3 and 4 results is not available, they provided no clear support for the hypothesis that the level of beer sales is directly related to the frequency of alcohol-related crash involvement.

Results for residual cross-correlations between beer sales and injury-producing traffic crashes, however, are consistent with hypothesized effects. Significant concurrent and lag 1 positive correlations were found between beer sales and the number of drinking drivers involved in injury crashes, after controlling for seasonal effects. Correlations at lags 2 through 5 were not significant, as expected.

Examination of the relationship between wine sales and both property-damage and injury-producing crashes revealed significant correlations only at lag 1 (Table 2). The observed .30 and .33 correlations are moderately high, and indicate that distribution of wine at the wholesale level is related to the number of drinking drivers involved in crashes one month later. The lack of a significant concurrent relationship between wine sales and crashes, as was found for beer sales and injury crashes, may reflect the longer lead time from wholesale distribution to consumption for wine than beer.

Finally, the large simultaneous correlation between spirits sales and alcohol-related crashes seen in Table 1 disappears when the seasonal effects are controlled (Table 2). The ARIMA model for spirits distribution accounts for 98 per cent of the total variance (see appendix); the small amount of remaining variance may partially explain the lack of a significant relationship between spirits distribution and alcohol-related crashes. In any event, this finding confirms the suggestion made earlier that the high lag 0 correlation is a reflection of similar seasonal cycles in both spirits sales and alcohol-related crashes.

\section{Discussion}

Results reported here provide considerable support for the hypothesis that the aggregate quantity of alcoholic beverages consumed in a community is related to the frequency of drinking drivers involved in motor vehicle crashes. Part of the association between alcohol consumption and alcohol-related crash involvement is due to congruent annual cycles in both drinking and alcoholrelated crashes. Such congruent cycles may reflect a causal effect of aggregate drinking on crash involvement. On the other hand, they may also be due to the common influence of exogenous seasonal factors. After controlling for seasonal effects, significant relationships remained between beer and wine consumption and the number of drinking drivers involved in crashes. That is, a random change in the quantity of beer or wine distributed in a given month is positively related to the number of crashinvolved drinking drivers in that same month and the following month. The lag structure observed was consistent with that expected, given the nature of the wholesale alcohol distribution indicators used. 
Distilled spirits distribution is highly correlated with the number of crash-involved drinking drivers. The high correlation reflects a similar seasonal cycle in spirits consumption and alcohol-related crashes. After eliminating the seasonal cycles from both spirits distribution and crashes, no significant cross-correlation remains. The cyclic similarity between spirits consumption and traffic crashes may reflect a causal relationship between the two variables. However, the presence of other confounding seasonal factors means a causal interpretation must be made cautiously.

Further research is needed. The cross-lagged correlation approach used here should be extended by developing and testing parametric time-series (i.e., transfer function) models. Such models should include multiple independent variables likely to influence the frequency of alcoholrelated crash involvement. Important variables might include general macroeconomic conditions, motor vehicle travel mileage, and changing patterns of driving, drinking, and driving-after-drinking. Analyses of motor vehicle crashes not related to alcohol have revealed the complexity of developing such multivariate time-series models [8]. The multiple independent or interactive effects of factors such as economic conditions on drinking behaviour and driving behaviour further complicate such analyses. Nevertheless, initial findings reported here of significant relationships between aggregate alcohol consumption and the incidence of alcohol-related crashes, even after filtering out trends and cycles, indicate the potential utility of this line of research.

Results of the present study demonstrate that there are significant relationships between the aggregate level of alcoholic beverage consumption in a community and the incidence of acute alcohol-related problems. If these relationships reflect an underlying causal relationship between consumption levels and the incidence of acute alcohol-related problems, measures aimed at reducing the aggregate consumption of alcoholic beverages will significantly reduce the frequency of acute alcohol-related problems such as traffic crashes. The best way to determine whether the significant observed relationships between aggregate alcohol consumption and acute alcohol-related problems identified here reflect causal relationships is through continued careful evaluation of alternative policies designed to reduce alcohol consumption and associated damage. The research reported here demonstrates that a focus on policies designed to reduce aggregate consumption may be a useful approach for the prevention of alcohol-related problems.

\section{References}

1 Bruun, K., Edwards, G., Lumio, M. and others. (1975). Alcohol Control Policies in Public Health Perspective. Helsinki, Finland: The Finnish Foundation for Alcohol Studies.

2 Popham, R., Schmidt, W. and deLint, J. (1978). Government Control Measures to Prevent Hazardous Drinking. In: J. A. Ewing and B. A. Rouse (eds.), Drinking: Alcohol in American Society - Issues and Current Research, pp. 239-266. Chicago: Nelson-Hall.

3 Aldoory, S. (1979/80). ABC Laws: An Overview. Alcohol Health and Research World, 4, 2-10.

4 Skog, O-J. (1980). Liver Cirrhosis Epidemiology: Some Methodological Problems. British fournal of Addiction, 75, 227-243.

5 Wagenaar, A. C. (1983). Alcohol, Young Drivers, and Traffic Accidents. Lexington, Massachusetts: D. C. Heath and Co.

6 Cook, T. D., Dintzer, L. and Mark, M. M. (1980). The Causal Analysis of Concomitant Time Series. In: L. Bickman (ed.), Applied Social Psychology Annual, vol. 1, pp. 93-135. Beverly Hills, California: Sage Publications.

7 Box, G. E. P. and Jenkins, G. M. (1976). Time Series Analysis: Forecasting and Control. Revised Edition. San Francisco: Holden-Day.

8 Wagenaar, A. C. (1984). Effects of Macroeconomic Conditions on the Incidence of Motor Vehicle Accidents. Accident Analysis and Prevention, 16, 191-205.

\section{Appendix}

Auto-regressive integrated moving average models for alcoholic beverage sales and traffic accidents

Beer distribution

$$
\begin{aligned}
& \qquad \mathrm{Y}_{\mathrm{t}}=\frac{\left(1-.91 \mathrm{~B}^{12}\right)(1+.30 \mathrm{~B}) \mathrm{u}_{\mathrm{t}}+3825}{1-\mathrm{B}^{12}} \\
& \text { Adjusted } \mathrm{R}^{2}=.74 \quad \mathrm{Q}=27 \text { with } 21 \text { d.f. }
\end{aligned}
$$

Wine distribution

$$
\begin{aligned}
\mathrm{Y}_{\mathrm{t}} & =\frac{\left(1-.83 \mathrm{~B}^{12}\right) \mathrm{u}_{\mathrm{t}}+37995}{1-\mathrm{B}^{12}} \\
\text { Adjusted } \mathrm{R}^{2} & =.59 \quad \mathrm{Q}=24 \text { with } 22 \text { d.f. }
\end{aligned}
$$

Spirits distribution

$$
\begin{aligned}
\qquad \mathrm{Y}_{\mathrm{t}} & =\frac{\left(1-.84 \mathrm{~B}^{12}\right) \mathrm{u}_{\mathrm{t}}+21086}{1-\mathrm{B}^{12}} \\
\text { Adjusted } \mathrm{R}^{2} & =.98 \quad \mathrm{Q}=13 \text { with } 22 \text { d.f. }
\end{aligned}
$$

Alcohol-related property-damage accidents

$$
\mathrm{Y}_{\mathrm{t}}=\frac{\left(1-.87 \mathrm{~B}^{12}\right)(1-.73 \mathrm{~B}) \mathrm{u}_{\mathrm{t}}}{\left(1-\mathrm{B}^{12}\right)(1-\mathrm{B})}
$$

$$
\text { Adjusted } \mathrm{R}^{2}=.74 \quad \mathrm{Q}=9 \text { with } 22 \text { d.f. }
$$

Alcohol-related injury accidents

$$
\begin{aligned}
\log \mathrm{Y}_{\mathrm{t}} & =\frac{\left(1-.85 \mathrm{~B}^{12}\right)(1-.68 \mathrm{~B}) \mathrm{u}_{\mathrm{t}}}{\left(1-\mathrm{B}^{12}\right)(1-\mathrm{B})} \\
\text { Adjusted } \mathrm{R}^{2} & =.70 \quad \mathrm{Q}=18 \text { with } 22 \text { d.f. }
\end{aligned}
$$


This document is a scanned copy of a printed document. No warranty is given about the accuracy of the copy. Users should refer to the original published version of the material. 